\title{
Rainfall Comparison from Different Precipitation Estimates over West Africa
}

\author{
I. A. Balogun'1, R. A. Balogun'1, T. Ademola ${ }^{2}$ \\ ${ }^{1}$ Department of Meteorology and Climate Science, Federal University of Technology, Akure, Nigeria \\ ${ }^{2}$ Nigerian Meteorological Agency (NIMET), Abuja, Nigeria \\ Email: rabalogun@futa.edu.ng
}

How to cite this paper: Balogun, I.A., Balogun, R.A. and Ademola, T. (2018) Rainfall Comparison from Different Precipitation Estimates over West Africa. Atmospheric and Climate Sciences, 8, 15-28. https://doi.org/10.4236/acs.2018.81002

Received: October 12, 2017

Accepted: December 30, 2017

Published: January 2, 2018

Copyright $\odot 2018$ by authors and Scientific Research Publishing Inc. This work is licensed under the Creative Commons Attribution International License (CC BY 4.0).

http://creativecommons.org/licenses/by/4.0/

\begin{abstract}
Comparison of different instantaneous precipitation estimates over three climatic zones in West Africa was carried out using Tropical Rainfall Measurement Mission (TRMM), 3A12 and 3A25 algorithms, the 3B43 rainfall product, and rain gauge product from the Global Precipitation Climatology Center (GPCC) as ground truth. The 3A12 rainfall product is observed to over-estimate rainfall intensity during MAM and JJAS periods, in all the zones, except in Guinea where it is observed to under-estimate rainfall intensity during the JJAS season. It was also observed that Savannah and Sahel had substantial frequency (occurrences) of zero $(0 \mathrm{~mm} / \mathrm{hr})$ rainfall intensities during MAM, but only the Sahel zone indicated high frequencies of $0 \mathrm{~mm} / \mathrm{hr}$ rainfall intensities during JJAS. The mean $3 \mathrm{~A} 12$ rainfall indicated substantial disparity with that of the gauge (GPCC) rainfall especially in Guinea and Savannah. During peak rainfall season (JJAS) all the rainfall products under-estimate rainfall in Guinea and Sahel region of West Africa, but over-estimates rainfall in the Savannah region, whereas during low rainfall episodes (MAM), all the rainfall products over estimate rainfall when compared with the gauge (GPCC) rainfall product. The Gauge (GPCC)-3B43 had the best relationship (highest correlation) in all the three zones during MAM. All the rainfall products showed very strong correlation with Gauge (GPCC) in all the zones in West Africa during the March-May (MAM) period. The Gauge (GPCC)-3B43 correlation maintained the best relationship with Gauge (GPCC) among the rainfall products, during JJAS.
\end{abstract}

\section{Keywords}

Instantaneous Precipitation Estimates, Rainfall Product

\section{Introduction}

Recent understanding of rainfall estimation from satellite sensors was achieved 
from past intercomparison programs, which were conducted during the last two decades, to investigate the various rainfall algorithms. For instance, the third Algorithm Intercomparison Program (AIP-3) coordinated by the GPCP in the framework of the World Climate Research Program (WCRP) analysed and compared different rainfall estimates from over 50 algorithms with groundbased radar data in the TOGA-COARE oceanic region from November 1992 to February 1993. While detailing the results from AIP-3, [1] indicated that there is a better correlation of the Microwave (MW) techniques with the validation data when compared with the Infra-Red (IR) or combined IR/MW techniques for instantaneous rainfall estimation, whereas, for monthly rainfall mean, the combined IR/MW techniques performed better than the other rainfall estimation techniques [1].

Other studies, both global and regional, indicated the relevance of techniques that combine gauge and satellite data when compared to techniques not applying any calibration (e.g. [2] and [3]). As regard the various rainfall products obtained from TRMM data detailed in [4], [5] presented the results obtained after two years in orbit of TRMM satellite and the deviations among the Microwave (MW), Infra-Red (IR), and combined IR/MW.

Advanced algorithms have been proposed by several authors, which were developed to produce surface rainfall estimates averaged on short time scales to satisfy the larger scientific community. For example, [6] conducted a validation study using surface data from two different dense rain gauge networks located in Tropical Africa, at various temporal resolution, for surface rainfall products obtained by using different source data. Three surface rainfall satellite products were considered at the 1-day timescale; 1) The RACC product obtained from geo-IR data calibrated by TRMM Microwave Imager (TMI) Microwave (MW) data accumulated for 1-day and 1-degree grid boxes, 2) The TRMM 3B42 product, which combines geo-IR and TMI-MW data, and 3) The GPCP one degree-daily product combines geo-IR, SSMI MW and gauge analyses. A microwave-based satellite rainfall product was also considered: it was computed from the MW data delivered by all the available SSMI's, but it is cumulated for 5-day.

[7] showed that the correlation coefficients, from [6], were low for the three satellite products at the daily time scale, and coefficients of about 0.7 were reached with time integration for time accumulation of at least 5 days. The performance obtained for GPCP one degree daily is slightly better than for TRMM $3 \mathrm{~B} 42$, showing the improvement introduced by the use of the gauge analysis, while the RACC product which is mainly from the IR data were less performing, according to [7]. The SSMI 5-day product showed poor performances, mainly due to the very bad time sampling of MW data. [7] demonstrated that the performances get better when all the source data (satellite geo-IR and MW data and gauge data) were used together.

Similar results regarding the performance of short timescale satellite rainfall products were given by [8] who compared the GPCP one degree daily precipita- 
tion field with the high-resolution precipitation data from dense surface networks of the BALTEX countries. For precipitation amounts, the comparison results indicated differences between gauge data and satellite data, which were higher on a daily time scale than on a monthly time scale, and indicated that the resolution of one degree and one day could be too high for quantitative applications. Nevertheless the GPCP one degree daily estimates showed well the time development of the large-scale spatial precipitation systems.

[9] performed an extensive evaluation of two categories of products. The first category had low spatial $\left(2.5^{\circ}\right)$ and temporal (monthly) resolution and included the GPCP) the National Oceanographic and Atmospheric Administration Climate Prediction Center (NOAA-CPC) merged analysis (CMAP), and the TRMM-3B 43 . The second category comprised relatively high spatial $\left(0.1^{\circ}\right.$ to $\left.1^{\circ}\right)$ and temporal (3-hourly to 10-daily) resolution products. These included the NOAA-CPC African rainfall estimation algorithm, GPCP one-degree-daily (1DD), TRMM-3B42, Tropical Applications of Meteorology using SATellite and other data (TAMSAT) estimates, and the CPC morphing technique (CMORPH). These products were aggregated to a 10-day total and rescaled to spatial resolutions of $1^{\circ}, 0.5^{\circ}$ and $0.25^{\circ}$. [9] revealed that TRMM-3B43 and CMAP from the first category and CMORPH, TAMSAT and TRMM-3B42 from the second category performed reasonably well.

[10] described a detailed investigation of a new high-resolution gauge-satellite-based analysis of daily precipitation over continental South America during 2004. The methodology adopted by [10] is based on a combination of additive and multiplicative bias correction schemes to get the lowest bias when compared with the observed values. The technique by [10] appeared to be a suitable tool to generate high-resolution and real-time, gauge-based and satellite-based analyses of daily precipitation over land in various regions.

[11] performed a comparison of precipitation estimates from near-real-time of satellite observations and numerical models. The results from [11] confirmed that the reliability of satellite precipitation estimates and the model quantitative precipitation forecasts (QPFs) are both highly dependent on the rainfall regime, and essentially opposed to each other-numerical models are most accurate during winter and at higher latitudes, while satellite estimates of rainfall show the greatest skill during summer and at lower latitudes. [11] further showed that the more the precipitation regime tends toward deep convective system, the less (more) accurate the model (satellite) estimates will be.

[12] evaluated four satellite-derived rainfall products (CMORPH, PERSIANN, TMPA-RT, and TMPA-V6) with regards to their reliability in capturing extreme precipitation. The results of [12] showed that CMORPH and PERSIANN rainfall products indicated better precipitation estimates. However, the false alarm ratio (FAR) and volume of CMORPH and PERSIANN data sets are higher than those of TMPA-RT and TMPA-V6. According to [12], no single rainfall product can be considered perfect for detecting extreme precipitation events. 
[13] assessed the suitability of NASA's TRMM 3B42 Version 6 rainfall product, and the satellite-based NOAA Climate Prediction Center (CPC) morphing technique (CMORPH), for assimilation applications in hydrological land data. [13] showed that at seasonal or annual time scales, CMORPH has much higher biases and RMS errors than TRMM 3B42. CMORPH shows season-dependent biases, which underestimate in winter and overestimate in summer. This leads to $50 \%$ higher RMS errors in CMORPH's area-averaged daily precipitation than TRMM 3B42. At higher temporal resolution (5 days or less), CMORPH uncertainty is slightly less, and about $10 \%-20 \%$ higher chances of detection of rainfall events than TRMM 3B42. In addition, the satellite estimates detect more high-intensity events, causing a remarkable shift in precipitation spectrum.

\section{Data and Methodology}

Three instantaneous (level 3) surface rainfall products (i.e. 3A12, 3A25, and 3B43 in TRMM data classification) from the TRMM precipitation radar (TPR) and GPCC Monthly regional rain gauge data (derived from the Global Precipitation Climatology Centre) were used in this research which span between 1998-2014. The 3A12 dataset is based on the TRMM 2A12 TMI retrieval algorithm. The 3A12 data sets are monthly averaged values of the surface rain rate (or intensity). The 3A25 dataset is based on the TRMM 2A25 PR retrieval algorithm. This dataset are monthly averaged values of the surface rain rate (or intensity). The 3B43 is TRMM merged product with other satellite product (3B42). Monthly regional rain gauge data are derived from the Global Precipitation Climatology Centre (GPCC). The analysis is performed on a $2.5^{\circ} \times 2.5^{\circ}$ grid based on an objective analysis technique presented by [14]. This resolution makes it compatible with most blended and satellite products. The GPCC gauge-only dataset is based on a network of stations that varies from about 500 to 600 stations per month in 1988 to approximately 2500 stations in 1994. The data sources are quality-controlled globally via exchanged synoptic weather reports ("SYNOP") and monthly climate reports ("CLIMAT"). The GPCC gauge dataset is interpolated to points that have no gauges [15].

Although the PR (Precipitation Radar) and TMI (TRMM Microwave Imager) sensors are on board the same satellite, significant differences exist in inter-annual variability of regional mean rainfall between rain estimates from the PR and TMI. As a result, intensity and frequency of TRMM and multi-satellite/gauge merged climate rainfall products were analysed and compared over West Africa using GPCC (Global Precipitation Climatology Center) data as ground truthing.

Analysis and plots are restricted to two seasonal time scales of March-May (MAM) and June-September (JJAS), because of low rainfall in the other months of October-February. Two kinds of validation methodology were carried out. In the first, the rainfall intensity and frequency fields for MAM and JJAS season for various TRMM products were compared. 
The second exercise/methodology is the estimation of error statistics for MAM and JJAS season. The bias is calculated as the difference between the satellite mean and the gauge mean, and the rms error is calculated after the bias is removed from the satellite estimate.

The statistical approaches used for the validation are as follows:

1) the Root Mean Square Error (RMSE), which measures the average error magnitude but gives greater weight to the larger errors, expressed as:

$$
\sqrt{\frac{\sum\left(f\left(x_{i}\right)-y_{i}\right)^{2}}{n}}
$$

where $x_{i}$ indicates the estimated value at a point or grid box $i, y_{i}$ indicates the observed value, and $\mathrm{n}$ is the number of samples.

2) The mean absolute error (MAE) measures the average magnitude of the error. It is given as:

$$
\text { Mean Absolute Error }=\frac{1}{n} \sum_{i=1}^{n}\left|x_{i}-y_{i}\right|
$$

3) The linear correlation coefficient (CC). this is expressed as:

$$
r=\frac{\sum_{i=1}^{n}\left(x_{i}-\bar{x}\right)\left(y_{i}-\bar{y}\right)}{\sqrt{\sum_{i=1}^{n}\left(x_{i}-\bar{x}\right)^{2}} \sqrt{\sum_{i=1}^{n}\left(y_{i}-\bar{y}\right)^{2}}}
$$

where $x_{i}$ indicates the estimated value at a point or grid box $i, y_{i}$ indicates the observed value, and $\mathrm{n}$ is the number of samples.

The map of the study area, showing the three zones under investigation, Figure 1 is as shown below.

\section{Results and Discussion}

\subsection{Frequency and Intensity Analysis Using Cumulative Distribution Functions during Mam and JJAS}

Figures 2(a)-(c) showed the frequency and intensity distribution for all

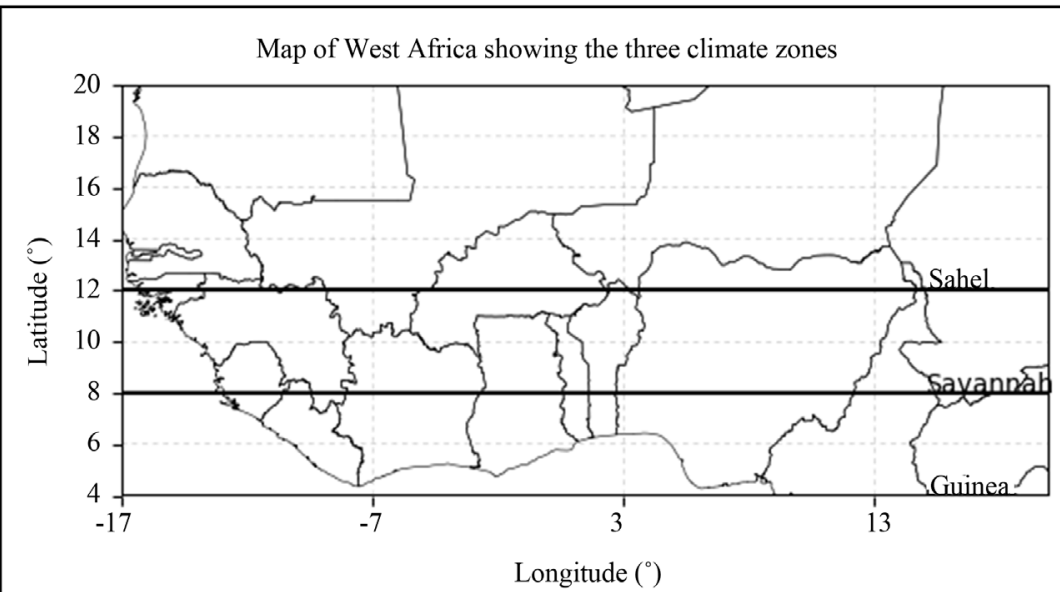

Figure 1. Showing the three zones in the study area. 


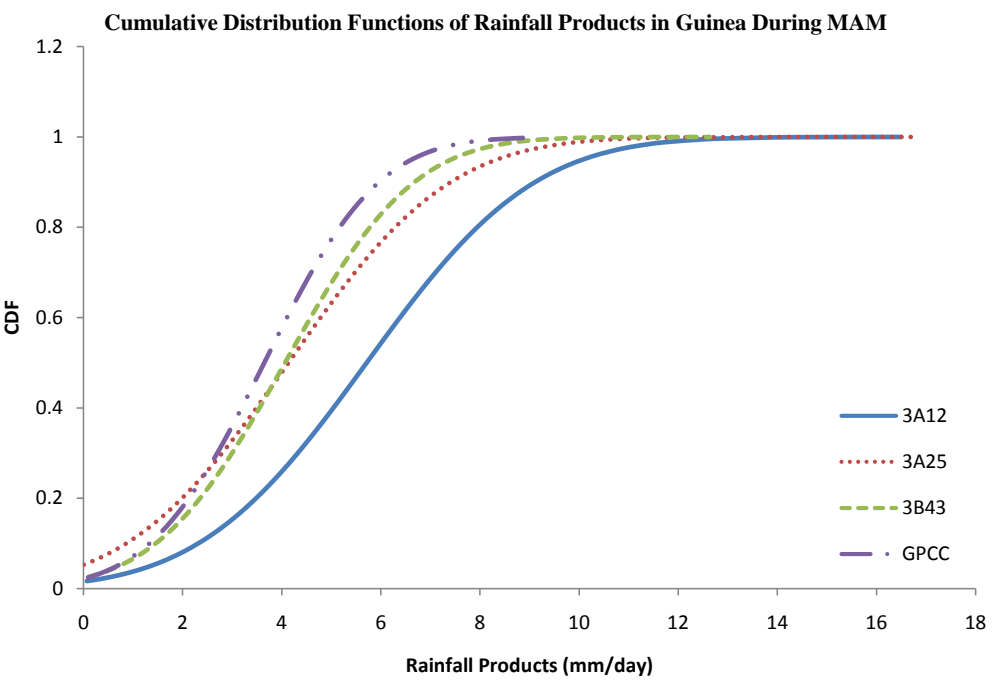

(a)

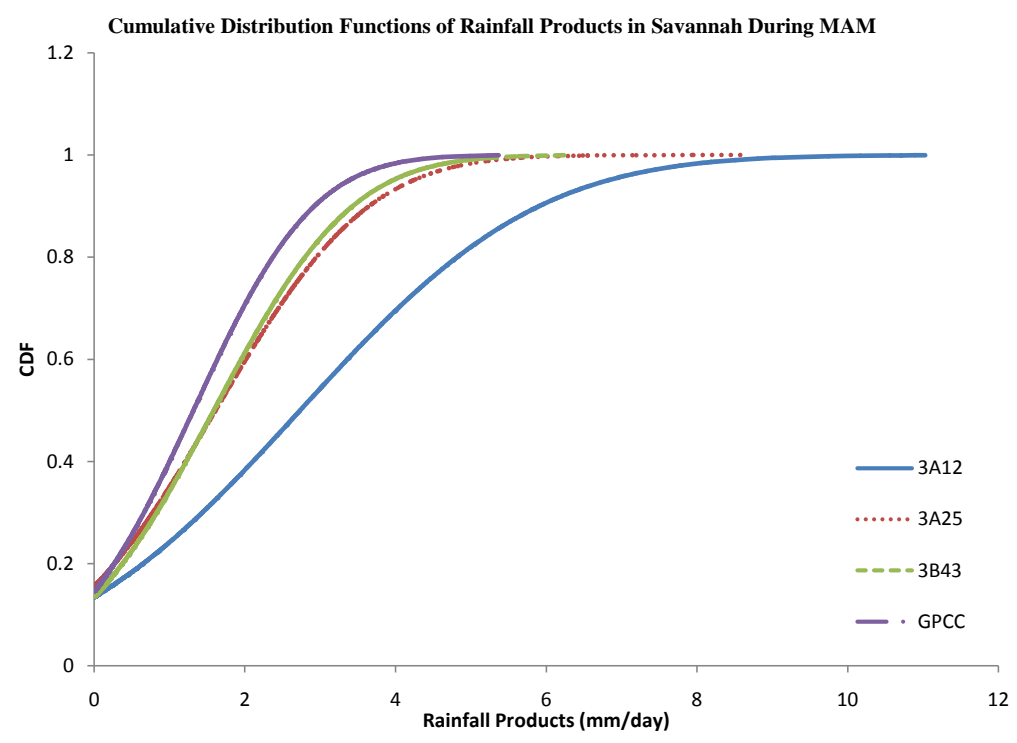

(b)

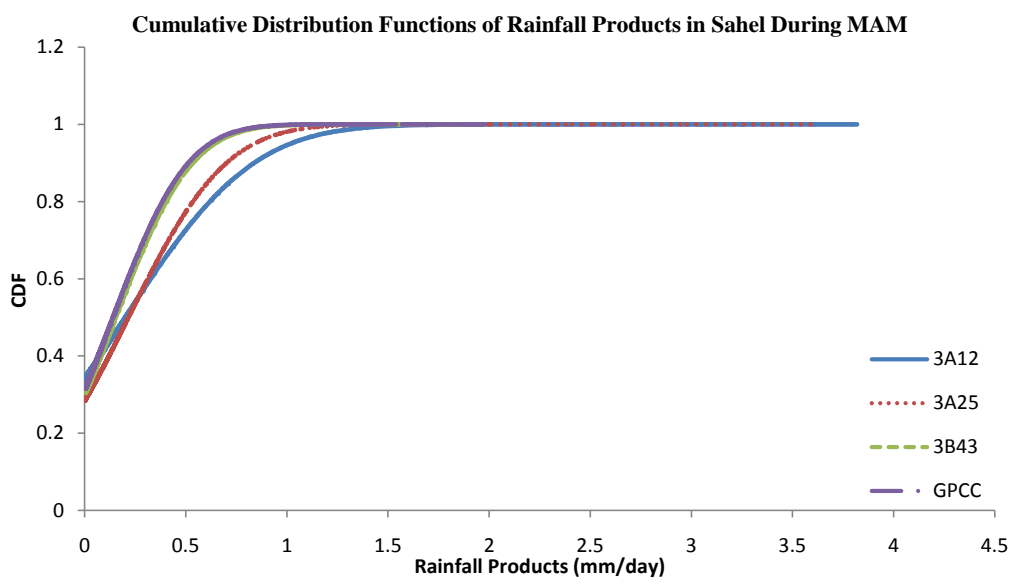

(c)

Figure 2. (a)-(c) Showing Cumulative Distribution Functions (CDF) in Guinea, Savannah, and Sahel during MAM. 
the four (4) rainfall products in each zone under investigation. In Figure 2(a) (Guinea), the 3A12 rainfall product indicated higher intensity than the other three (3) rainfall products. It is obvious that, below $50 \%$ of the distribution, frequency and intensity are almost the same for the other three rainfall products (3A25, 3B43 and GPCC), with a little spread, between $50 \%$ and $90 \%$ of the distribution. All the rainfall products reached peak intensities between $12 \mathrm{~mm} /$ day and $17 \mathrm{~mm} /$ day, but with very few occurrences (frequencies). In Figure 2(b) (Savannah) above, the same pattern is observed as in Figure 2(a) (Guinea). Figure 1 (b) indicated that the $3 \mathrm{~A} 12$ rainfall product estimated rainfall at a higher intensity than the other three (3) products. The 3A12 and 3A25 rainfall products, which are pure TRMM rainfall products from TRMM's TMI and TRMM's $P R$ respectively, showed higher number of occurrences (frequencies) of high intensity rainfall than the gauge (GPCC) and the 3B43 rainfall products. A close observation shows that the overall rainfall intensity had decreased in Savannah when compared to Guinean zone. Figure 2(c) represents the CDF of the rainfall products in Sahel region. The Figure showed that the overall intensity had decreased further when compared to Savannah and Guinean Zones. About $70 \%$ of the rainfall, in this zone, is below $0.5 \mathrm{~mm}$ /day during MAM, $30 \%$ of the $70 \%$ is completely $0 \mathrm{~mm} /$ day during the MAM period. The maximum observed or estimated rainfall in this zone is below $4 \mathrm{~mm} /$ day as indicated by the $3 \mathrm{~A} 12$ and $3 \mathrm{~A} 25$ rainfall products. The 3B43 and gauge (GPCC) rainfall products indicated maximum intensities below $2 \mathrm{~mm}$ /day in the Sahel zone. With this, it can be concluded that rainfall intensity generally decreases with latitude during March to May (MAM) period in West Africa.

The same investigation is performed for June to September (JJAS) period/ season, which is mostly characterised by increased rainfall when compared to the MAM period. In Figure 3(a) (Guinean zone), the gauge (GPCC) and the 3B43 rainfall products had higher intensities compared to the other two (2) rainfall products (3A12 and 3A25). $10 \%-95 \%$ (representing $85 \%$ of the total rainfall in this zone), had intensities between $2.5 \mathrm{~mm}$ /day and $12.5 \mathrm{~mm} /$ day. This observation indicates that rainfall is most frequent within these intensities range of $2.5 \mathrm{~mm} /$ day and $12.5 \mathrm{~mm}$ /day in the Guinean zone during JJAS. Only $5 \%$ of the total rainfall had intensities within the range of $12.5 \mathrm{~mm} /$ day and 20 $\mathrm{mm} /$ day, as observed by all the rainfall products in Guinea. In Figure 3(b) (Savannah zone), the highest observed or estimated intensities were indicated by the $3 \mathrm{~A} 25$ and $3 \mathrm{~B} 43$ rainfall products, but the intensities observed or estimated by the $3 \mathrm{~A} 12$ and the $3 \mathrm{~B} 43$, between $0 \%-99 \%$, were generally higher than the other two (2) rainfall products. Both Guinea and Savannah zones peak between 20 $\mathrm{mm} /$ day and $25 \mathrm{~mm} /$ day. The pattern of the distribution is slightly different for the Sahel zone, as shown in Figure 3(c) (Sahel) above. In this zone, about 20\% of the total rainfall distribution indicated no rainfall ( $0 \mathrm{~mm} /$ day intensity). $20 \%$ $99 \%$ (about $80 \%$ proportion) had rainfall intensities below $8 \mathrm{~mm} /$ day while only about $1 \%$ of rainfall occurrences had intensities between $8 \mathrm{~mm} /$ day and maximum of $14 \mathrm{~mm} /$ day, on the average, in the Sahel. 


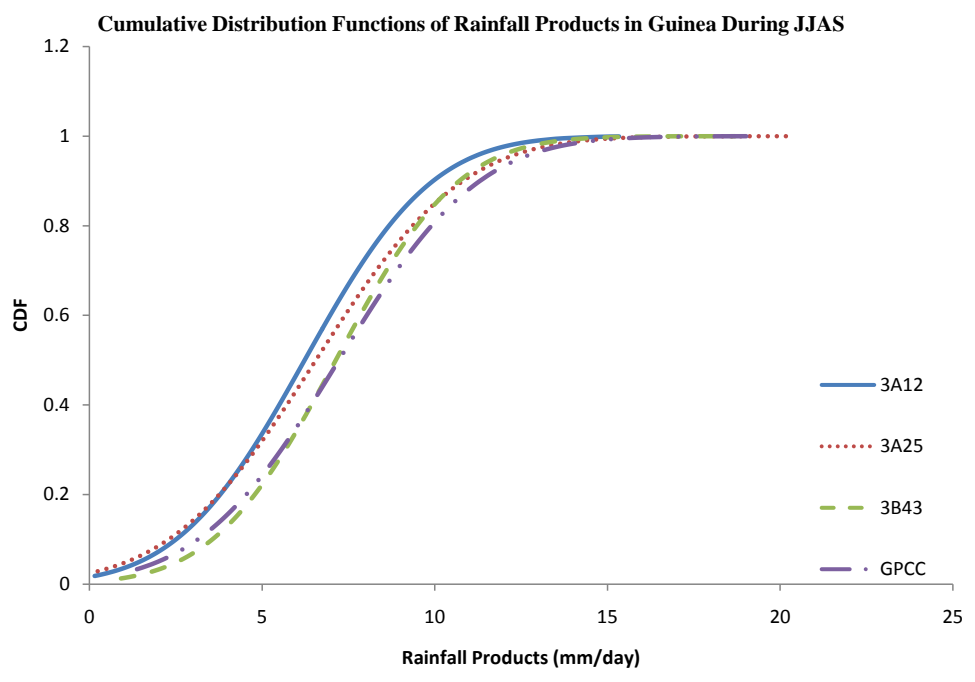

(a)

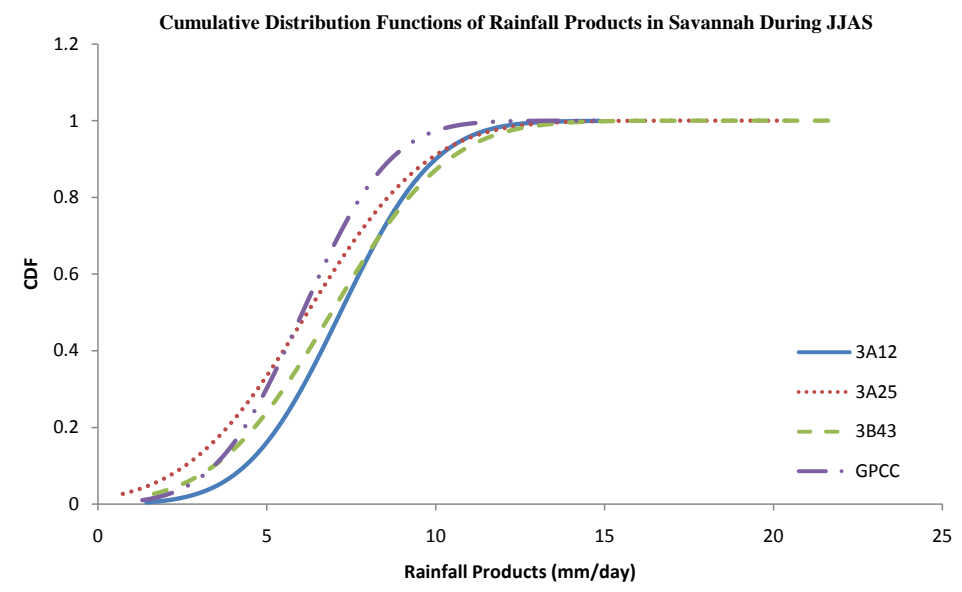

(b)

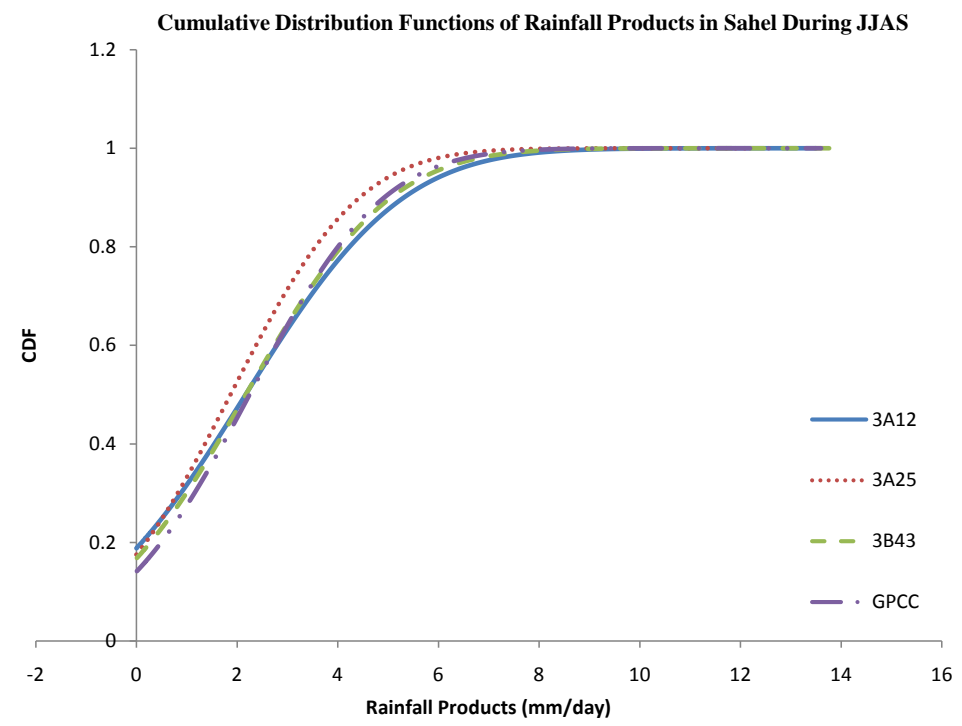

(c)

Figure 3. (a)-(c) Showing Cumulative Distribution Functions (CDF) in Sahel during JJAS. 


\subsection{Average Rainfall Intensity during MAM and JJAS}

The comparison of mean rainfall intensity of all the four (4) rainfall products for each zone during MAM and JJAS are shown in Figure 4(a)-(c). The results, as shown in Figure 4(a) and Figure 4(c), indicated that, on the average, rainfall intensity decreases from Guinea to Sahel in MAM and JJAS, but in JJAS the rainfall intensity in Guinea and Savannah are almost the same. In Sahel, as shown in Figure 4(a) during MAM, all the products indicated very low rainfall intensities, on the average, which are almost the same, in Sahel, the 3A12 rainfall product had the highest mean intensity, while in Guinea, the $3 \mathrm{~A} 12$ also indicated the highest rainfall mean intensity, compared to the other rainfall products. In Figure 4(c) during JJAS, all the rainfall products are almost the same for Sahel zone except for the 3A25 rainfall product. In Savannah, the mean 3B43 and $3 \mathrm{~A} 12$ rainfall products are almost the same whereas the $3 \mathrm{~A} 25$ and gauge (GPCC)

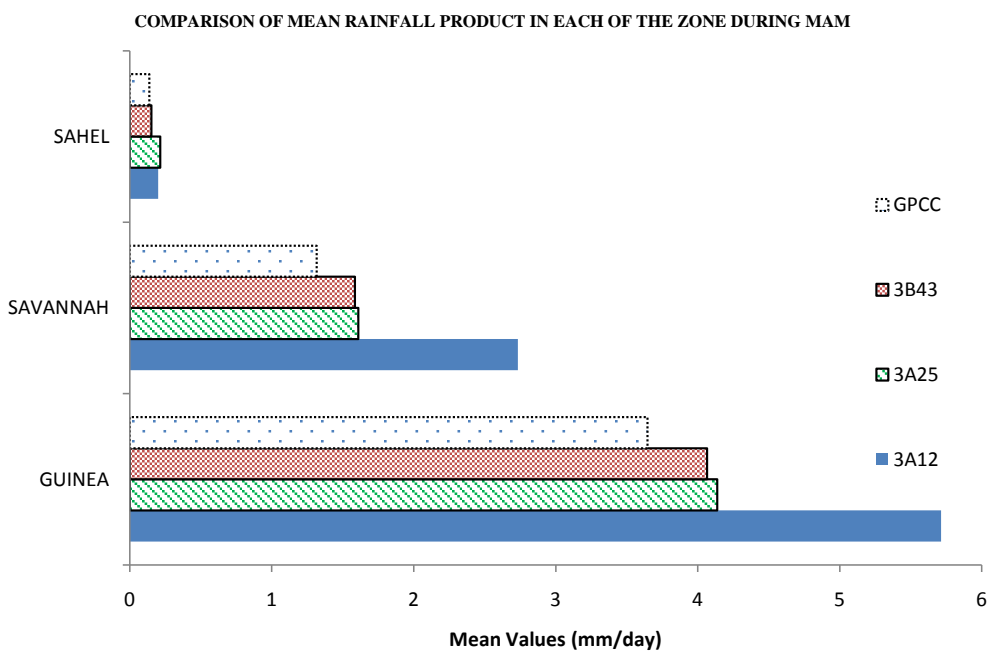

(a)

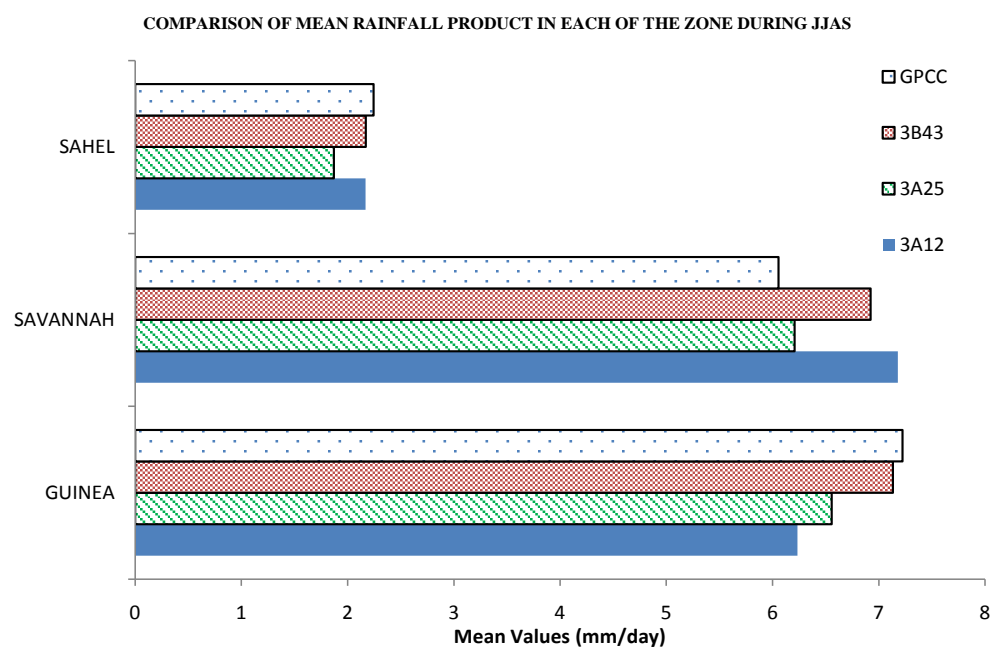

(c)

Figure 4. (a) and (c) Showing averaged rainfall intensities during JJAS. Note that (b) and (d) are not shown. 
rainfall products exhibited close mean value in Savannah. The Guinea zone during JJAS showed that the gauge (GPCC) rainfall product had the highest mean value, followed by $3 \mathrm{~B} 43$ rainfall product, then $3 \mathrm{~A} 25$ rainfall product and finally $3 \mathrm{~A} 12$ rainfall product.

This had clearly shown that during peak rainfall episodes, as in JJAS, all the rainfall products under estimate rainfall in Guinea and Sahel, but overestimate rainfall in the Savannah zone, whereas during low rainfall episodes, as in MAM, all the rainfall products over estimate rainfall when compared to gauge (GPCC) rainfall product.

\subsection{Correlation, Regression and Statistical Errors}

The correlation among the rainfall products are tabulated in Table 1 below. The Gauge (GPCC)-3A12 correlation is the least observed correlation (0.707329) or relationship among the products in Guinea during MAM, while the Gauge (GPCC)-3B43 relationship has the highest correlation (0.874176) in Guinea during MAM. The Gauge (GPCC)-3A25 relationship has the least correlation (0.8186) in Savannah during MAM, also the Gauge (GPCC)-3B43 relationship has the highest correlation (0.919766) in Savannah during MAM. The table also showed that the Gauge (GPCC)-3A25 relationship had the least correlation in Sahel during MAM, and as inferred in Guinea and Savannah, the Gauge (GPCC)-3B43 relationship is nearly perfectly correlated in Sahel During MAM. With this tabulated information, it can be deduced that the 3A12 rainfall product/algorithm does not perform well in the Guinea zone which is closer to the Atlantic Ocean but improved in observation inland. The 3B43 rainfall product/algorithm is the best performing algorithm among the rainfall products and it also improved inland. The 3A25 rainfall product which had the least relationship with Gauge (GPCC) also improved inland. All the rainfall products showed

Table 1. Correlation between each of the Rainfall Products during MAM.

\begin{tabular}{ccccc}
\hline GUINEA_MAM & GPCC & 3A12 & 3A25 & 3B43 \\
\hline 3A12 & 0.71 & 1 & & \\
3A25 & 0.77 & 0.78 & 1 & 1 \\
3B43 & 0.87 & 0.77 & 0.84 & 3B43 \\
SAVANNAH_MAM & GPCC & 3A12 & 3A25 & \\
3A12 & 0.87 & 1 & & 1 \\
3A25 & 0.82 & 0.89 & 1 & 3B43 \\
3B43 & 0.92 & 0.95 & 0.88 & \\
SAHEL_MAM & GPCC & $3 \mathrm{~A} 12$ & $3 \mathrm{~A} 25$ & \\
3A12 & 0.91 & 1 & & 1 \\
3A25 & 0.86 & 0.87 & 0.87 & \\
3B43 & 0.97 & 0.94 & & \\
\hline
\end{tabular}


very strong positive correlation with Gauge (GPCC) in all the zones in West Africa during the March-May (MAM) period.

Table 2 below showed that the Root Mean Square Error (RMSE) is always larger than the Mean Absolute Error (MAE). The lower the value of the RMSE, the better is the relationship, and so the results tabulated in Table 2 revealed that the RMSE decreases from Guinea to Sahel for each of the rainfall products. It is also observed that the RMSE decreases from $3 \mathrm{~A} 12$ to $3 \mathrm{~A} 25$, and then from $3 \mathrm{~A} 25$ to $3 \mathrm{~B} 43$. Thus $3 \mathrm{~B} 43$ has the least error among the rainfall products.

Because rainfall amount, frequency, and intensity are high during the JJAS season, especially in the Guinean zone, results Tabulated in Table 3 showed that correlation is moderate between Gauge (GPCC) and 3A12 rainfall product, with an improved relationship between Gauge (GPCC) and 3A25, which improved further between Gauge (GPCC) and 3B43 rainfall product. In Savannah, also in Table 3, the correlation also improved with rainfall product as were observed in Guinea zone, but in Savannah the correlation is much better than were observed in Guinea zone. The relationship in Sahel is a little different. In Sahel, Gauge

Table 2. Root Mean Square and Mean Absolute errors of each product with respect to GPCC.

\begin{tabular}{ccccc}
\hline RMSE & GPCC & 3A12 & 3A25 & 3B43 \\
\hline GUINEA & & 2.791049 & 1.704016 & 1.074611 \\
SAVANNAH & & 2.07475 & 0.960323 & 0.629985 \\
SAHEL & & 0.270369 & 0.209168 & 0.078569 \\
MAE & GPCC & $3 \mathrm{A12}$ & $\mathbf{3 A 2 5}$ & $\mathbf{3 B 4 3}$ \\
GUINEA & & 2.223287 & 1.204025 & 0.722445 \\
SAVANNAH & & 1.430379 & 0.584866 & 0.331425 \\
SAHEL & & 0.106353 & 0.110171 & 0.041025 \\
\hline
\end{tabular}

Table 3. Correlation between each of the Rainfall Products during JJAS.

\begin{tabular}{ccccc}
\hline GUINEA & GPCC & 3A12 & 3A25 & 3B43 \\
\hline 3A12 & 0.49 & 1 & & \\
3A25 & 0.61 & 0.72 & 1 & 1 \\
3B43 & 0.73 & 0.73 & 0.86 & 3B43 \\
SAVANNAH & GPCC & $3 \mathrm{~A} 12$ & $3 \mathrm{~A} 25$ & \\
3A12 & 0.54 & 1 & & 1 \\
3A25 & 0.69 & 0.69 & 1 & $3 \mathrm{~B} 43$ \\
3B43 & 0.88 & 0.68 & 0.82 & \\
SAHEL & GPCC & $3 \mathrm{~A} 12$ & $3 \mathrm{~A} 25$ & \\
3A12 & 0.90 & 1 & & 1 \\
3A25 & 0.88 & 0.89 & 0.91 & \\
3B43 & 0.98 & 0.93 &
\end{tabular}


(GPCC)-3A12 had a slightly better correlation than the Gauge (GPCC)-3A25 correlation. The Gauge (GPCC)-3B43 correlation maintained the best relationship with Gauge (GPCC) among the rainfall products.

The Root Mean Square Error (RMSE) for JJAS, in Table 4, also decreases with increasing latitude in West Africa, and also decreases with the rainfall products from $3 \mathrm{~A} 12$ to $3 \mathrm{~A} 25$, to $3 \mathrm{~B} 43$ rainfall product, which implied that the $3 \mathrm{~B} 43$ rainfall product estimate rainfall better than the other two (2) rainfall products when compared with Gauge (GPCC) rainfall product.

\section{Conclusions}

This research work had compared observed frequencies and intensities of rainfall estimates from different measurement systems, comprising Tropical Rainfall Measurement mission (TRMM, 3A12 and 3A25 algorithms), the 3B43 rainfall product (The 3B43 combines the estimates generated by the TRMM and other satellites product (3B42) and the CAMS global gridded rain gauge data, produced by NOAA's Climate Prediction Center (CPC) and/or the global rain gauge product produced by the Global Precipitation Climatology Center (GPCC)), and the GPCC as in-situ data for ground truthing.

Rainfall intensity generally decreases with latitude during March to May (MAM) period in West Africa, with the TRMM's 3A12 rainfall product showing stronger intensity, in Guinea, Savannah and Sahel, than the other three rainfall products. Both Guinea and Savannah zones peak between $20 \mathrm{~mm} /$ day and 25 $\mathrm{mm} /$ day. The pattern of the distribution is slightly different for the Sahel zone, as about $20 \%$ of the total rainfall distribution indicated no rainfall $(0 \mathrm{~mm} /$ day intensity). $20 \%$ - 99\% (about $80 \%$ proportion) had rainfall intensities below 8 $\mathrm{mm} /$ day while only about $1 \%$ of rainfall occurrences had intensities between 8 $\mathrm{mm} /$ day and maximum of $14 \mathrm{~mm} /$ day, on the average, in the Sahel. The 3A12 rainfall product over estimate rainfall during MAM period, but under estimate rainfall in Guinea during the JJAS season. The 3A12 rainfall product also over estimate rainfall in Savannah during the JJAS season, but in Sahel both during MAM and JJAS, the $3 \mathrm{~A} 12$ rainfall had close average values with the gauge

Table 4. Root Mean Square and Mean Absolute errors of each product with respect to GPCC.

\begin{tabular}{ccccc}
\hline RMSE & GPCC & 3A12 & 3A25 & 3B43 \\
\hline GUINEA & & 3.230 & 2.956 & 2.232 \\
SAVANNAH & & 2.325 & 2.065 & 1.582 \\
SAHEL & & 1.093 & 1.0621 & 0.523 \\
MAE & GPCC & $3 \mathrm{~A} 12$ & $3 \mathrm{~A} 25$ & $3 \mathrm{~B} 43$ \\
GUINEA & & 2.324 & 2.096 & 1.435 \\
SAVANNAH & & 1.801 & 1.529 & 1.022 \\
SAHEL & & 0.7510 & 0.751 & 0.358 \\
\hline
\end{tabular}


(GPCC, which represented ground truth observation) rainfall product. The other rainfall products (3B43 and 3A25) also over estimate rainfall in Savannah both during MAM and JJAS, but under estimate rainfall in Guinea during JJAS.

This had clearly shown that during peak rainfall episodes, as in JJAS, all the rainfall products under estimate rainfall in Guinea and Sahel, but overestimate rainfall in the Savannah zone, whereas during low rainfall episodes, as in MAM, all the rainfall products over estimate rainfall when compared to gauge (GPCC) rainfall product.

A view of the intensities and frequencies of each of the rainfall products in each of the zones indicated that rainfall intensities are generally high in Guinea when compared to the other two (2) zones; also intensities are generally high in Savannah when compared to Sahel zone, as indicated by each of the rainfall product during MAM. During JJAS, 3A12 rainfall product estimated stronger intensities, in Savannah zone, than the other two zones. The 3A25 and 3B43 rainfall products exhibited almost the same intensities and frequencies for the Guinea and Savannah zones, whereas, the GPCC indicated stronger intensities and frequencies in the Guinea zone when compared to the Savannah and Sahel zones.

The Gauge (GPCC)-3B43 had the best relationship (highest correlation) in all the three zones during MAM. The 3B43 rainfall product/algorithm is the best performing algorithm among the rainfall products and it also improved inland. The 3A25 rainfall product which had the least relationship with Gauge (GPCC) also improved inland. All the rainfall products showed very strong positive correlation with Gauge (GPCC) in all the zones in West Africa during the March-May (MAM) period. The Gauge (GPCC)-3B43 correlation maintained the best relationship with Gauge (GPCC) among the rainfall products, during JJAS.

\section{References}

[1] Ebert, E.E. and Manton, M.J. (1998) Performance of Satellite Rainfall Estimation Algorithms during TOGA COARE. Journal of the Atmospheric Sciences, 55, 1537-1557. https://doi.org/10.1175/1520-0469(1998)055<1537:POSREA >2.0.CO;2

[2] Laurent, H., Jobard, I. and Toma, A. (1998) Validation of Satellite and Ground-Based Estimates of Precipitation over the Sahel. Atmospheric Research, 47-48, 651-670. https://doi.org/10.1016/S0169-8095(98)00051-9

[3] Thorne, V., Coakeley, P., Grimes, D. and Dugdale, G. (2001) Comparison of TAMSAT and CPC Rainfall Estimates with Raingauges, for Southern Africa. International Journal of Remote Sensing, 22, 1951-1974. https://doi.org/10.1080/01431160118816

[4] Kummerow, C., Barnes, W., Kozu, T., Shiue, J. and Simpson, J. (1998) The Tropical Rainfall Measuring Mission (TRMM) Sensor Package. Journal of Atmospheric and Oceanic Technology, 15, 809-816. https://doi.org/10.1175/1520-0426(1998)015<0809:TTRMMT>2.0.CO;2

[5] Kummerow, C. and Coauthors (2000) The Status of the Tropical Rainfall Measuring Mission (TRMM) after Two Years in Orbit. Journal of Applied Meteorology and 
Climatology, 39, 1965-1982.

https://doi.org/10.1175/1520-0450(2001)040<1965:TSOTTR >2.0.CO;2

[6] Ramage, K., Jobard, I., Lebel, T. and Desbois, M. (2000) Satellite Estimation of 1-Day to 10-Day Precipitation: Comparison and Validation over Tropical Africa of TRMM, METEOSAT and GPCP Products. Proceeding the 2000 EUMETSAT Meteorological Satellite Data User's Conference, Bologna, 29 May-2 June 2000, 363-369.

[7] Jobard, I. and Desbois, M. (1994) Satellite Estimation of the Tropical Precipitation Using the Meteosat and SSM/I Data. Atmospheric Research, 34, 285-298. https://doi.org/10.1016/0169-8095(94)90097-3

[8] Rudolph, B. (2000) Satellite-Based Global Precipitation Estimates and Validation Results. Proceeding EUMETSAT SAF Training Workshop: Climate Monitoring, Dresden, 20-22 November 2000, 140-149.

[9] Dinku, T., Ceccato, P., Grover-Kopec, E., Lemma, M., Connor, S.J. and Ropelewski, C.F. (2007) Validation of Satellite Rainfall Products over East Africa's Complex Topography. International Journal of Remote Sensing, 28, 1503-1526. https://doi.org/10.1080/01431160600954688

[10] Vila, D., Ferraro, R. and Joyce, R. (2007) Evaluation and Improvement of AMSU Precipitation Retrievals. Journal of Geophysical Research, 112, D20119. https://doi.org/10.1029/2007JD008617

[11] Ebert, E.E., Janowiak, J.E. and Kidd, C. (2007) Comparison of near Real-Time Precipitation Estimates from Satellite Observations and Numerical Models. The Bulletin of the American Meteorological Society, 88, 47-64. https://doi.org/10.1175/BAMS-88-1-47

[12] Agha Kouchak, A., Behrangi, A., Sorooshian, S., Hsu, K. and Amitai, E. (2011) Evaluation of Satellite-Retrieved Extreme Precipitation Rates across the Central United States. Journal of Geophysical Research, 116, D02115.

[13] Tian, Y., Peters-Lidard, C., Choudhury, B. and Garcia, M. (2007) Multitemporal Analysis of TRMM-Based Satellite Precipitation Products for Land Data Assimilation Applications. Journal of Hydrometeorology, 8, 1165-1183. https://doi.org/10.1175/2007JHM859.1

[14] Rudolf, B. (1993) Management and Analysis of Precipitation Data on a Routine Basis. Proceedings of International World Meteorological Organization (WMO)/International Association of Hydrological Sciences (IAHS)/Eidgenössische Technische Hochschule (ETH) Symposium on Precipitation and Evaporation, Bratislava, 20-24 September 1993, Slovak Hydrometeorology Institute, 69-76.

[15] Rudolf, B., Hauschild, W., Rueth, W. and Schneider, U. (1994) Terrestrial Precipitation Analysis: Operational Method and Required Density of Point Measurements. In: Desbois, M. and De'salmand, F., Eds., Global Precipitations and Climate Change, NATO ASI Series, 26, 173-186.

https://doi.org/10.1007/978-3-642-79268-7_10 